\title{
Differences in physical activity according to mMRC grade in patients with COPD
}

\author{
This article was published in the following Dove Press journal: \\ International Journal of COPD \\ 13 September 2016 \\ Number of times this article has been viewed
}

\author{
Atsushi Hayata' \\ Yoshiaki Minakata ${ }^{2}$ \\ Kazuto Matsunaga ${ }^{3}$ \\ Masanori Nakanishi' \\ Nobuyuki Yamamoto' \\ 'Third Department of Internal \\ Medicine, Wakayama Medical \\ University, School of Medicine, \\ Wakayama, ${ }^{2}$ Department of \\ Respiratory Medicine, National \\ Hospital Organization Wakayama \\ Hospital, Wakayama, ${ }^{3}$ Department of \\ Respiratory Medicine and Infectious \\ Disease, Graduate School of Medicine, \\ Yamaguchi University, Yamaguchi, Japan
}

Correspondence: Yoshiaki Minakata Department of Respiratory Medicine, National Hospital Organization Wakayama Hospital, II 38 Wada, Mihama-cho, Hidaka-gun, Wakayama

Tel +81738223256

Fax +81738222126

Email minakaty@wakayama2.hosp.go.jp 644-0044, Japan

Background: Physical activity (PA) is impaired from the early stages of COPD, is associated with a worsening of disease prognosis, and causes COPD patients to restrict their daily activities in order to avoid breathlessness. The development of a simple tool to estimate physical activity level (PAL) could be useful for the management of COPD.

Objectives: We investigated the differences in PA according to the modified Medical Research Council (mMRC) grade in patients with COPD.

Methods: A cross-sectional study was performed on stable outpatients with COPD. PA was measured for 2 weeks using a triaxial accelerometer, and dyspnea grade was evaluated in all patients using the mMRC scale.

Results: Ninety-eight patients were recruited. Significant differences in PA duration were observed at all intensities according to the mMRC grade. Despite treatment with controller medications, 59.2\% of COPD patients had low PAL, which was $<1.5$ metabolic equivalents multiplied by hour per day. COPD patients with an mMRC grade $\geq 2$, which was the most balanced cutoff point in the receiver operating characteristic curve, showed a higher reduction rate of PAL (80.0\% at mMRC grade 2, 71.4\% at mMRC grade 3 , and $100 \%$ at mMRC grade 4 ).

Conclusion: PA differed according to the $\mathrm{mMRC}$ grade, and mMRC grade $\geq 2$ could predict a low PAL. Therefore, assessment of breathlessness by the mMRC questionnaire would be useful to stratify the risks of reduced PA in COPD.

Keywords: accelerometer, questionnaire, dyspnea, METs

\section{Introduction}

COPD is characterized by persistent airflow limitation that is associated with an enhanced chronic inflammatory response to noxious particles or gases in the airways and lungs. ${ }^{1}$ It was reported that COPD was the third leading cause of death in 2012 by the World Health Organization. ${ }^{2}$ Patients with COPD often have limited daily physical activity (PA). The level of PA was reported to be associated with decline of lung function and increase in hospitalizations. ${ }^{3,4}$ Moreover, the decline of daily PA was shown to be the strongest predictor of mortality in patients with COPD. ${ }^{5}$ Recently, an accelerometer was used for evaluating PA in COPD because of its accuracy. We have validated triaxial accelerometers ${ }^{6,7}$ and have evaluated the features of $\mathrm{PA}^{8}$ and the efficacy of medication for PA in COPD. ${ }^{9}$ However, equipment and several days for evaluation are required.

The modified Medical Research Council (mMRC) Questionnaire is widely used for assessing the severity of breathlessness in patients with COPD. This questionnaire was reported to be consistent with other measures of health status and to predict the decline of lung function and future mortality risk. ${ }^{10-12}$ Although the severity of breathlessness is assumed to be associated with PA, the differences in PA in patients 
with COPD according to the mMRC grade have not yet been clearly established. We hypothesized that the mMRC grade could detect low PA in patients with COPD.

The aim of this study was to investigate the differences in PA measured by a triaxial accelerometer according to the $\mathrm{mMRC}$ grade and also to investigate the $\mathrm{mMRC}$ grade that can detect low PA in patients with COPD.

\section{Methods}

\section{Subjects}

Stable COPD patients (aged $\geq 60$ years) following treatment in accordance with the guidelines and without any other diseases that might interfere with walking were recruited from among the outpatients of Wakayama Medical University Hospital. COPD was diagnosed if the following condition existed: a postbronchodilator forced expiratory volume in 1 second $\left(\mathrm{FEV}_{1}\right)$ /forced vital capacity of $<0.7$. The patients were excluded if they had any other pulmonary diseases, such as asthma and bronchiectasis, or experienced exacerbations during the 4 weeks prior to the study.

\section{Protocol}

Patients' age, sex, height, weight, smoking status, treatments, mMRC grade, spirometry, and PA were examined in a crosssectional manner. Each patient wore a triaxial accelerometer, Actimarker (Panasonic, Osaka, Japan), for 2 weeks in order to measure their PAs. Written informed consent was obtained from all patients, and the study was approved by the local ethics committee (Institutional Review Board committee of Wakayama Medical University; authorization number: 968) and was registered with University Hospital Medical Information Network (UMIN) center (UMIN 000006293).

\section{Assessment of PA}

The Actimarker is a small $(74.5 \times 13.4 \times 34.0 \mathrm{~mm})$ and lightweight $(36.0 \mathrm{~g})$ accelerometer that is worn only at the waist and can be continuously monitored for over 1 month. The Actimarker has already been validated for evaluating PA in COPD in terms of intensity. ${ }^{7}$ From the 2 weeks of monitored data, 3 consecutive nonrainy weekdays from the beginning, except the first and last days, were extracted, and the mean values of PA duration from the extracted 3 days were employed as representative values of PA for the individual according to a previous investigation.?

In addition, we calculated the PA level (PAL) that was the value of metabolic equivalents multiplied by their durations (METs-hour). The American College of Sports Medicine and the American Heart Association recommended that older adults need moderate-intensity (between 3 METs and 6 METs) aerobic PA for a minimum of 0.5 hours for 5 days of each week. ${ }^{13}$ Therefore, we regarded the patients with PAL $<1.5$ METs.hour as those with low PA.

\section{Assessment of mMRC grade}

The mMRC grade is a five-point scale based on the severity of a patient's breathlessness related to PA. Current guidelines advocate the use of this scale to assess symptoms. ${ }^{1}$ In this study, the mMRC grades were assessed by the study physicians.

\section{Statistical analysis}

Statistical analysis was performed using GraphPad Prism 5 (GraphPad Software, Inc., La Jolla, CA, USA). KruskalWallis test and post hoc Dunn's multiple comparison test were used for comparison of PA durations and PAL among the patients of each mMRC grade. Chi-square test was used for comparison of the proportion of patients with low PAL among the mMRC grades. Using a receiver operating characteristic (ROC) curve, we determined the cutoff points for identifying the patients with low PAL. A $P$-value of $<0.05$ was considered significant.

\section{Results}

Ninety-eight patients with COPD were included in this study, and the characteristics of the included patients are shown in Table 1. Ninety-two patients $(93.9 \%)$ were males, and the numbers of patients with Global Initiative for Chronic Obstructive Lung Disease (GOLD) stages I, II, III, and IV were 14 (14.3\%), 50 (51\%), 22 (22.4\%), and 12 (12.2\%), respectively.

Significant differences in the PA duration according to the $\mathrm{mMRC}$ grade were confirmed at all intensities ( $\geq 2$ METs: $P=0.01, \geq 2.5$ METs: $P=0.01, \geq 3$ METs: $P=0.01, \geq 3.5$ METs: $P=0.05$ by Kruskal-Wallis test) (Figure 1A-D). With the post hoc analysis, the reduction of the PA duration was significant for the patients with mMRC grades 3 and 4 at $\geq 2.0$ METs (Figure $1 \mathrm{~A}$ ) and with mMRC grades 2 and 3 at $\geq 2.5$ METs (Figure 1B), as compared to those with $\mathrm{mMRC}$ grade 1 .

The PAL, which was calculated by METs.hour at $\geq 3$ METs, was also significantly different according to the mMRC grade $(P<0.005$; Figure 2$)$. However, there were no significant differences among the mMRC grades by the multiple comparison test. 
Table I Characteristics of patients

\begin{tabular}{|c|c|c|c|c|c|c|}
\hline Characteristics & Total & mMRC 0 & mMRC I & mMRC 2 & mMRC 3 & $\overline{\mathrm{mMRC}} 4$ \\
\hline Sex (male/female), n & $92 / 6$ & $21 / 3$ & $34 / 2$ & $19 / 1$ & $14 / 0$ & $4 / 0$ \\
\hline Age (years) & $71.4 \pm 6.9$ & $68.3 \pm 6.8$ & $72.1 \pm 6.5$ & $71.5 \pm 7.9$ & $73.7 \pm 5.8$ & $72.5 \pm 9.9$ \\
\hline Smoking history (never/ex/current), n & $0 / 84 / 14$ & $0 / 19 / 5$ & $0 / 31 / 5$ & $0 / 20 / 0$ & $0 / 10 / 4$ & $0 / 4 / 0$ \\
\hline GOLD stage $(1 / 2 / 3 / 4), n$ & $14 / 50 / 22 / 12$ & $7 / 15 / 1 / 1$ & $5 / 24 / 5 / 2$ & $1 / 9 / 7 / 3$ & $1 / 2 / 8 / 3$ & $0 / 0 / 1 / 3$ \\
\hline \multicolumn{7}{|l|}{ Medication } \\
\hline LAMA, n (\%) & $68(69.4)$ & $10(41.7)$ & $24(66.7)$ & $17(85.0)$ & $14(100.0)$ & $3(75.0)$ \\
\hline LABA, n (\%) & $34(34.7)$ & $2(8.3)$ & $12(33.3)$ & $10(50.0)$ & $7(50.0)$ & $3(75.0)$ \\
\hline ICS/LABA, n (\%) & $28(28.6)$ & $7(29.2)$ & $6(16.7)$ & $8(40.0)$ & $6(42.9)$ & I $(25.0)$ \\
\hline \multicolumn{7}{|l|}{ Pulmonary function } \\
\hline $\mathrm{FVC}(\mathrm{L})$ & $3.28 \pm 0.72$ & $3.42 \pm 0.80$ & $3.40 \pm 0.57$ & $3.29 \pm 0.77$ & $2.96 \pm 0.44$ & $2.60 \pm 0.49$ \\
\hline $\mathrm{FEV}_{1}(\mathrm{~L})$ & $1.56 \pm 0.59$ & $1.98 \pm 0.58$ & $1.67 \pm 0.49$ & $1.35 \pm 0.49$ & $1.15 \pm 0.36$ & $0.72 \pm 0.09$ \\
\hline $\mathrm{FEV}_{\mathrm{I}} / \mathrm{FVC}(\%)$ & $47.1 \pm 13.4$ & $55.6 \pm 10.3$ & $46.7 \pm 12.5$ & $38.7 \pm 9.7$ & $36.5 \pm 11.2$ & $28.1 \pm 2.7$ \\
\hline FEV $\%$ predicted (\%) & $57.9 \pm 20.3$ & $68.6 \pm 16.9$ & $62.1 \pm 18.8$ & $48.1 \pm 15.6$ & $41.8 \pm 15.7$ & $29.1 \pm 4.6$ \\
\hline
\end{tabular}

Notes: Data are presented as mean \pm SD. mMRC measures are as follows; mMRC 0, I only get breathless with strenuous exercise; mMRC I, I get short of breath when hurrying on the level or walking up a slight hill; mMRC 2, I walk slower than people of the same age on the level because of breathlessness, or I have to stop for breath when walking on my own pace on the level; mMRC 3, I stop for breath after walking about 100 meters or after a few minutes on the level; mMRC 4 , I am too breathless to leave the house or I am breathless when dressing or undressing.

Abbreviations: mMRC, modified Medical Research Council; GOLD, Global Initiative for Chronic Obstructive Lung Disease; LAMA, long-acting muscarinic antagonist; LABA, long-acting $\beta 2$ agonist; ICS, inhaled corticosteroid; FVC, forced vital capacity; FEV , forced expiratory volume in I second; SD, standard deviation.
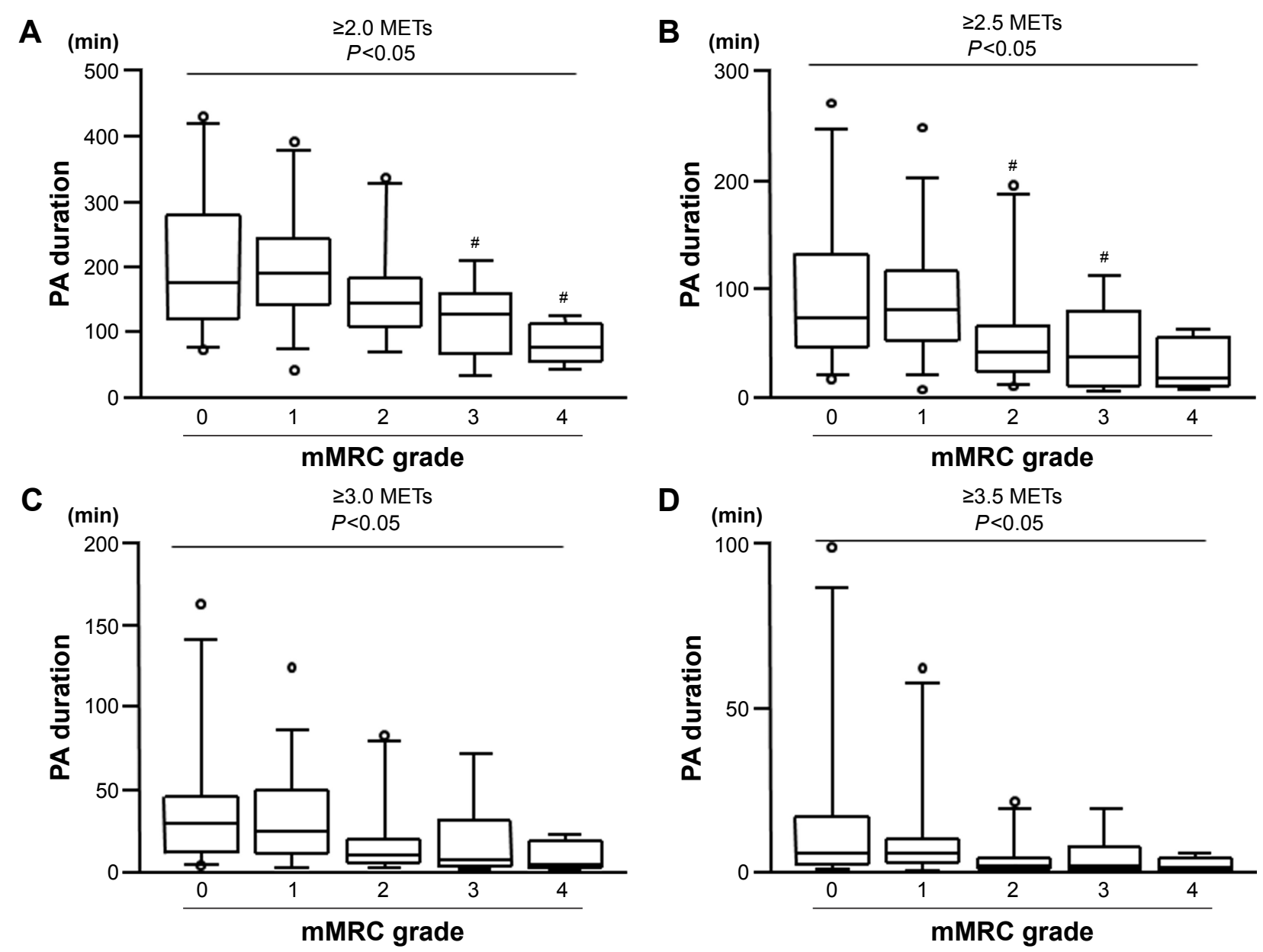

Figure I Differences in PA duration according to the mMRC grade.

Notes: Kruskal-Wallis test and post hoc Dunn's multiple comparison test were used for the comparison of PA durations according to the mMRC grade. Data are shown as a box plot (lower and upper extreme of the box represent the 25th and the 75th percentiles, respectively, and the central line represents the median). The lower and upper vertical lines represent the 5 th and 95 th percentiles, respectively. ${ }^{\#} \mathbf{P}<0.05$ versus $\mathrm{mMRC}$ grade I. A: PA at $\geq 2$ METs; B: PA at $\geq 2.5$ METs; C: PA at $\geq 3$ METs; D: PA at $\geq 3.5$ METs. Abbreviations: PA, physical activity; mMRC, modified Medical Research Council; METs, metabolic equivalents; min, minutes. 


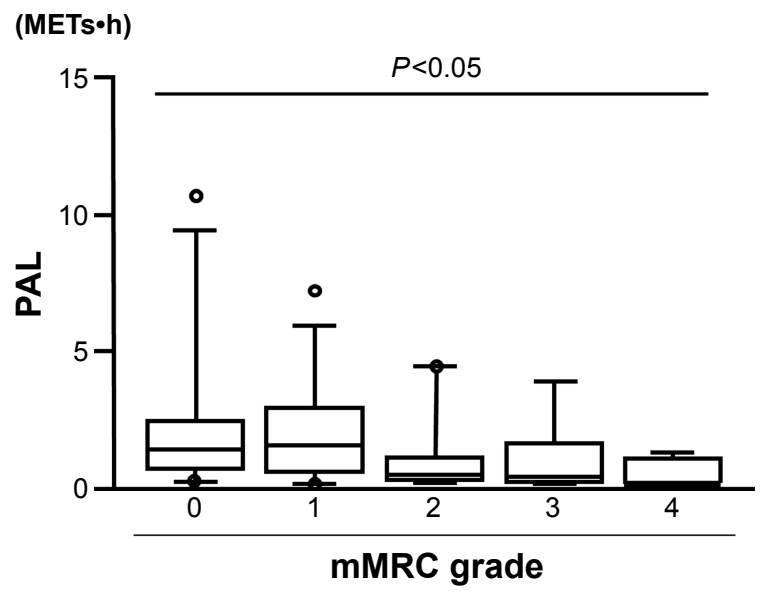

Figure 2 Differences in PAL at $\geq 3$ METs according to the $m M R C$ grade. Notes: Kruskal-Wallis test and post hoc Dunn's multiple comparison test were used for the comparison of PA durations according to the mMRC grade. Data are shown as a box plot (lower and upper extreme of the box represent the 25th and the 75th percentiles, respectively, and the central line represents the median). The lower and upper vertical lines represent the 5 th and 95 th percentiles, respectively. Abbreviations: PAL, physical activity level; mMRC, modified Medical Research Council; PA, physical activity; METs, metabolic equivalents; h, hour.

More than half of COPD patients $(59.2 \%)$ had a low PAL $<1.5$ METs.hour. Even among the patients with mMRC grade 0 , the proportion of those with low PAL was $45.8 \%$. The proportion of the patients with low PAL was significantly increased as the mMRC grade increased and significantly higher in patients with mMRC grades 2 and 4 than those with mMRC grades 0 and 1 (Figure 3 ).

Using an ROC curve for identifying the patients with low PAL, mMRC grade $\geq 2$ was the most balanced cutoff point and yielded $51.7 \%$ sensitivity and $80.0 \%$ specificity ( area under curve $=0.66$ ) (Figure 4).

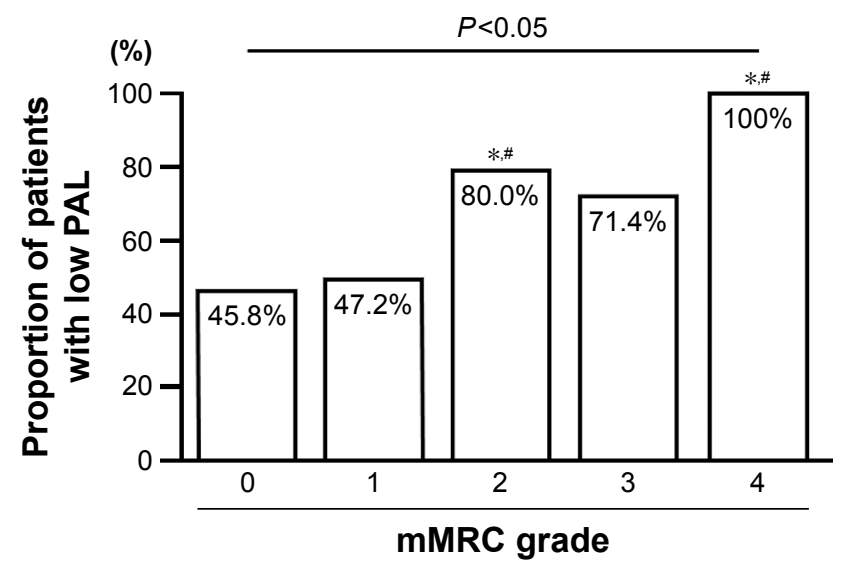

Figure $3 \mathrm{mMRC}$ grade and the proportion of patients with low PAL.

Notes: Chi-square test was used for comparison between mMRC grades and the proportion of patients with low PAL. ${ }^{*} P<0.05$ versus mMRC grade $0,{ }^{*} P<0.05$ versus $\mathrm{mMRC}$ grade $\mathrm{I}$.

Abbreviations: mMRC, modified Medical Research Council; PAL, physical activity level.

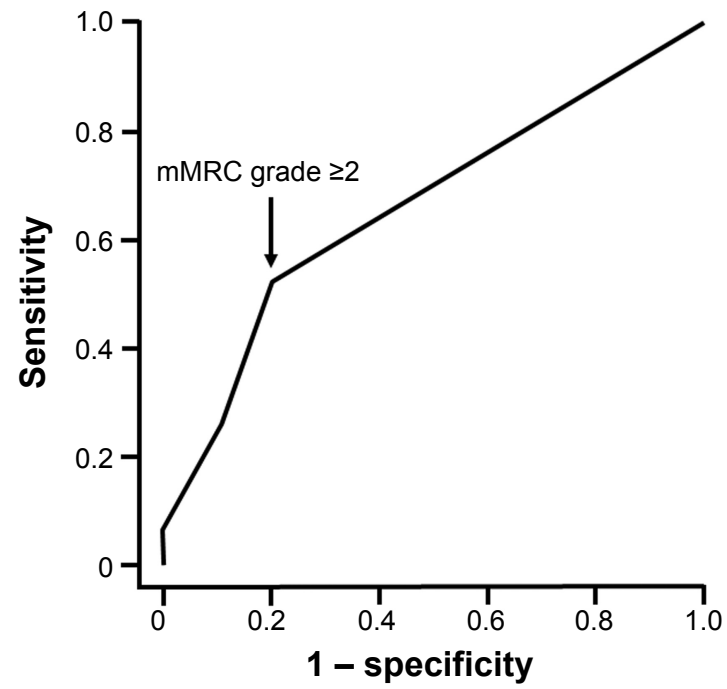

Figure 4 ROC curve for identifying patients with low PAL.

Notes: mMRC grade $\geq 2$ was the most balanced cutoff point and yielded $51.7 \%$ sensitivity and $80.0 \%$ specificity (area under curve $=0.66$ ).

Abbreviations: mMRC, modified Medical Research Council; PAL, physical activity level; ROC, receiver operating characteristic.

\section{Discussion}

We could demonstrate differences in PA duration or PAL measured by triaxial accelerometer according to the $\mathrm{mMRC}$ grade in patients with COPD. Among the COPD patients, $59.2 \%$ had low PAL, and even among the patients with mMRC grade 0 , low PAL was observed in $45.8 \%$ of them. An $\mathrm{mMRC}$ grade $\geq 2$ was the most balanced cutoff point for identifying patients with low PAL.

PA durations among the $\mathrm{mMRC}$ grades were significantly different at all intensities. Pitta et $\mathrm{al}^{14}$ reported that patients with COPD had shorter periods of walking time per day than healthy elderly individuals (44 minutes and 81 minutes, respectively). Sakamoto et a ${ }^{15}$ reported these values as 47.5 minutes in COPD and 106.5 minutes in healthy subjects. In our study, the mean PA duration at $\geq 3$ METs, which is the intensity of a normal walking speed for a healthy adult, was about 40 minutes in COPD patients with mMRC grades 0 and 1 , which is similar to previous reports. We previously reported that the reduction rate of PA in COPD patients was $50.9 \%$ at $\geq 3$ METs. $^{8}$

This study showed that the PAL was significantly different according to the $\mathrm{mMRC}$ grade, and the proportion of the patients with low PAL was significantly increased as the $\mathrm{mMRC}$ grade increased. Watz et $\mathrm{al}^{16}$ reported that the proportion of very inactive patients markedly increased in patients with an $\mathrm{mMRC}$ grade $\geq 2$ compared with chronic bronchitis, which seems to be consistent with our results. However, this was not statistically evaluated, and the differences in 
PA according to the mMRC grade in patients with COPD were not clearly demonstrated.${ }^{16}$ In this study, using an ROC curve for identifying the patients with low PAL, an mMRC grade $\geq 2$ was the most balanced cutoff point that yielded $51.7 \%$ sensitivity and $80.0 \%$ specificity. This result means that an mMRC grade $\geq 2$ strongly suggests a marked reduction of PA. The reason for the low sensitivity may be that not only breathlessness but also sociodemographic, lifestyle, and environmental factors, as well as other clinical and functional variables, affect the PA in patients with COPD. ${ }^{17}$ In GOLD,${ }^{1}$ mMRC grade $\geq 2$ was used as a cutoff point for stratifying the impact of COPD on an individual patient, which is compatible with our results.

GOLD has recommended adjusting the therapeutics by evaluating the degree of symptoms, breathlessness, airflow obstruction, and frequency of COPD exacerbations. ${ }^{1}$ In this study, the value of $\mathrm{FEV}_{1} \%$ predicted was correlated with the mMRC grade $(r=-0.559, P<0.0001)$ and PAL $(r=0.329$, $P<0.001$ with linear regression analysis). We previously reported an association between the severity of airflow obstruction and breathlessness assessed by the mMRC questionnaire. ${ }^{18}$ Moreover, this study showed that the mMRC questionnaire was a useful tool for estimating the level of daily PA. These results suggest that an objective evaluation of the breathlessness assessed by the mMRC questionnaire in daily practice could play an important role in improving COPD management.

However, in COPD patients, the efficacy of the pharmacological or the nonpharmacological treatments on dyspnea has been reported, ${ }^{19-22}$ but their efficacy in PA is still controversial. ${ }^{23-33}$ This discrepancy might occur because the effect of treatment on PA was modified by not only dyspnea but also other factors, including several clinical and functional variables. However, the dyspnea grade could be one of the important predictors of PA in COPD patients.

This study had several limitations. First, the number of recruited patients was small. A larger study will be required to determine the usefulness of the mMRC grade for estimating PA. Second, this study is based on a single center. Finally, potential comorbidities, including depression, osteoporosis, and muscular weakness, were not completely excluded, though the patients with diseases that might interfere with walking were excluded.

\section{Conclusion}

The PA in patients with COPD was different according to the mMRC grade. PAL was reduced compared to the American College of Sports Medicine/American Heart Association recommendation in about one half of the patients with $\mathrm{mMRC}$ grades 0 and 1 . However, the reduction rate of PAL was much higher in those with an mMRC grade $\geq 2$. The mMRC grade reflected the increases in the proportion of patients with low PAL. Moreover, mMRC grade $\geq 2$ was the most balanced cutoff point for stratifying the risks of reduced PAs in COPD. The mMRC questionnaire could be a useful tool for estimating the level of PA in daily life.

\section{Acknowledgments}

The authors thank Mr Brent Bell for reading the manuscript. This study was supported by JSPS KAKENHI grant numbers 24591136 and $15 \mathrm{KO} 9187$.

\section{Author contributions}

All authors contributed toward data analysis, drafting and critically revising the paper and agree to be accountable for all aspects of the work.

\section{Disclosure}

The authors report no conflicts of interest in this work.

\section{References}

1. Global initiative for Chronic Obstructive Lung Disease [homepage on the Internet]. Global Strategy for the Diagnosis, Management, and Prevention of Chronic Obstructive Disease. 2016. Available from: http://www.goldcopd.com. Accessed June 20, 2016.

2. World Health Organization [homepage on the Internet]. Available from: http://www.who.int/en/. Accessed June 20, 2016.

3. Garcia-Aymerich J, Lange P, Benet M, Schnohr P, Antó JM. Regular physical activity modifies smoking-related lung function decline and reduces risk of chronic obstructive pulmonary disease: a population-based cohort study. Am J Respir Crit Care Med. 2007;175(5):458-463.

4. Pitta F, Troosters T, Probst VS, Spruit MA, Decramer M, Gosselink R. Physical activity and hospitalization for exacerbation of COPD. Chest. 2006;129(3):536-544.

5. Waschki B, Kirstein A, Holz O, et al. Physical activity is the strongest predictor of all-course mortality in patients with COPD: a prospective cohort study. Chest. 2011;140(2):331-342.

6. Kanda M, Minakata Y, Matsunaga K, et al. Validation of the triaxial accelerometer for the evaluation of physical activity in Japanese patients with COPD. Intern Med. 2012;51(4):369-375.

7. Sugino A, Minakata Y, Kanda M, et al. Validation of a compact motion sensor for the measurement of physical activity in patients with chronic obstructive pulmonary disease. Respiration. 2012;83(4):300-307.

8. Minakata Y, Sugino A, Kanda M, et al. Reduced level of physical activity in Japanese patients with chronic obstructive pulmonary disease. Respir Investig. 2014;52(1):41-48.

9. Minakata Y, Morishita Y, Ichikawa T, et al. Effects of pharmacologic treatment based on airflow limitation and breathlessness on daily physical activity in patients with chronic obstructive pulmonary disease. Int J Chron Obstruct Pulmon Dis. 2015;10:1275-1282.

10. Bestall JC, Paul EA, Garrod R, Garnham R, Jones PW, Wedzicha JA. Usefulness of the medical research council (MRC) dyspneoa scale as a measure of disability in patients with chronic obstructive pulmonary disease. Thorax. 1999;54(7):581-586.

11. Oga T, Tsukino M, Hajiro T, Ikeda A, Nishimura K. Analysis of longitudinal changes in dyspnea of patients with chronic obstructive pulmonary disease: an observational study. Respir Res. 2012;13:85. 
12. Nishimura K, Izumi T, Tsukino M, Oga T. Dyspnea is a better predictor of 5-year survival than airway obstruction in patients with COPD. Chest. 2002;121(5):1434-1440.

13. Haskell WL, Lee IM, Pate RR, et al. Physical activity and public health: updated recommendation for adults from the American College of Sports Medicine and the American Heart Association. Med Sci Sports Exerc. 2007;39(8):1423-1434.

14. Pitta F, Troosters T, Spruit MA, Probst VS, Decramer M, Gosselink R. Characteristics of physical activities in daily life in chronic obstructive pulmonary disease. Am J Respir Crit Care Med. 2005; 171(9):972-977.

15. Sakamoto Y, Sakamoto K, Minakata Y, et al. Walking pattern in COPD patients. Rehabil Nurs. Epub Mar 14, 2015.

16. Watz H, Waschki B, Meyer T, Magnussen H. Physical activity in patients with COPD. Eur Respir J. 2009;33(2):262-272.

17. Gimeno-Santos E, Frei A, Steurer-Stey C, et al. PROactive consortium. Determinants and outcomes of physical activity in patients with COPD: a systematic review. Thorax. 2014;69(8):731-739.

18. Matsunaga K, Hayata A, Akamatsu K, et al. Stratifying the risk of COPD exacerbation using the modified Medical Research Council scale: a multicenter cross-sectional CAP study. Respir Investig. 2015;53(2):82-85.

19. Casaburi R, Mahlar DA, Jones PW, et al. A long-term evaluation of once-daily inhaled tiotropium in chronic obstructive pulmonary disease. Eur Respir J. 2002;19(2):217-224.

20. Bogdan MA, Aizawa H, Fukuchi Y, Mishima M, Nishimura M, Ichinose M. Efficacy and safety of inhaled formoterol 4.5 and $9 \mu \mathrm{g}$ twice daily in Japanese and European COPD patients: phase III study results. $B M C$ Pulm Med. 2011;11:51.

21. Buhl R, Dunn LJ, Disdier C, et al; INTENSITY Study Investigators. Blinded 12-week comparison of once-daily indacaterol and tiotropium in COPD. Eur Respir J. 2011;38(4):797-803.

22. Pulmoanry rehabilitation: joint ACCP/AACVPR evidence-based guidelines. ACCP/AACVPR Pulmonary Rehabilitation Guidelines Panel. American College of Chest Physicians. American Association of Cardiovascular and Pulmonary Rehabilitation. Chest. 1997; 112(5):1363-1396.

23. Hataji O, Naito M, Ito K, Watanabe F, Gabazza EC, Taguchi O. Indacaterol improves daily physical activity in patients with chronic obstructive pulmonary disease. Int J Chron Obstruct Pulmon Dis. 2013;8:1-5
24. Watz H, Krippner F, Kirsten A, Magnussen H, Vogelmeier C. Indacaterol improves lung hyperinflation and physical activity in patients with moderate chronic obstructive pulmonary disease - a randomized, multicenter, double-blind, placebo-controlled study. BMC Pulm Med. 2014; $14: 158$.

25. Beeh KM, Watz H, Puente-Maestu L, et al. Aclidinium improves exercise endurance, dyspnea, lung hyperinflation, and physical activity in patients with COPD: a randomized, placebo-controlled, crossover trial. BMC Pulm Med. 2014;14:209.

26. Minakata Y, Morishita Y, Hiramatsu M, et al. Effect of transdermal tulobuterol patch on the physical activity in eight male subjects with chronic obstructive pulmonary disease. Clin Res Pulmonol. 2014; 2:1010.

27. O’Donnell DE, Casaburi R, Vincken W, et al. INABLE 1 study group. Effect of indacaterol on exercise endurance and hyperinflation in COPD. Respir Med. 2011;105(7):1030-1036.

28. Troosters T, Sciurba FC, Decramer M, et al. Tiotropium in patients with moderate COPD naïve to maintenance therapy: a randomized placebo-controlled trial. NPJ Prim Care Respir Med. 2014;24:14003.

29. Sewell L, Singh SJ, Williams JE, Collier R, Morgan MD. Can individualized rehabilitation improve functional independence in elderly patients with COPD? Chest. 2005;128(3):1194-1200.

30. Mercken EM, Hageman GJ, Schols AM, Akkermans MA, Bast A, Wouters EF. Rehabilitation decreases exercise-induced oxidative stress in chronic obstructive pulmonary disease. Am J Respir Crit Care Med. 2005;172(8):994-1001.

31. Pitta F, Troosters T, Probst VS, Langer D, Decramer M, Gosselink R. Are patients with COPD more active after pulmonary rehabilitation? Chest. 2008;134(2):273-280.

32. Mador MJ, Patel AN, Nadler J. Effect of pulmonary rehabilitation on activity levels in patients with chronic obstructive pulmonary disease. J Cardiopulm Rehabil Prev. 2011;31(1):52-59.

33. Egan C, Deering BM, Blake C, et al. Short term and long term effects of pulmonary rehabilitation on physical activity in COPD. Respir Med. 2012;106(12):1671-1679.
International Journal of COPD

\section{Publish your work in this journal}

The International Journal of COPD is an international, peer-reviewed journal of therapeutics and pharmacology focusing on concise rapid reporting of clinical studies and reviews in COPD. Special focus is given to the pathophysiological processes underlying the disease, intervention programs, patient focused education, and self management protocols.

\section{Dovepress}

This journal is indexed on PubMed Central, MedLine and CAS. The manuscript management system is completely online and includes a very quick and fair peer-review system, which is all easy to use. Visit http://www.dovepress.com/testimonials.php to read real quotes from published authors. 